\title{
A vertical girdle fabric in the NorthGRIP deep ice core, North Greenland
}

\author{
Yun WANG, ${ }^{1}$ Thorsteinn THORSTEInSSON, ${ }^{1,2}$ Josef KIPFSTUHL, ${ }^{1}$ Heinz MILLER, ${ }^{1}$ \\ Dorthe DAHL-JENSEN, ${ }^{3}$ Hitoshi SHOJI ${ }^{4}$ \\ ${ }^{1}$ Department of Geophysics/Glaciology, Alfred Wegener Institute for Polar and Marine Research, P.O. Box 120161, D-27515 Bremerhaven, \\ Germany \\ E-mail: ywang@awi-bremerhaven.de \\ ${ }^{2}$ Department of Geophysics, Science Institute, University of Iceland, Dunhaga 3, IS-107 Reykjavik, Iceland \\ ${ }^{3}$ Niels Bohr Institute for Astronomy, Physics and Geophysics, University of Copenhagen, Juliane Maries Vej 30, DK-2100 Copenhagen, Denmark \\ ${ }^{4}$ New Energy Resources Research Center, Kitami Institute of Technology, 165 Koen-cho, Kitami 090-8507, Japan
}

\begin{abstract}
A high-resolution study of $c$-axis fabrics has been performed on the NorthGRIP deep ice core from North Greenland. A newly developed automatic ice-fabric analyzer has been used to measure $c$-axis orientations on vertical thin sections at 142 different depths between 100 and $2920 \mathrm{~m}$ in the core. Detailed comparison studies show that this new method produces results that are in full accordance with those obtained from conventional manual measurements. Fabric development in ice of the NorthGRIP core can be explained by rotation of $c$ axes, controlled by the prevailing stress systems. In the upper $800 \mathrm{~m}$ the $c$ axes appear to distribute uniformly, but in the depth interval 900-2500m they tend to cluster around a vertical plane. This vertical girdle pattern is strengthened with depth, forming the first clear evidence of this fabric type in a Greenland deep ice core. Such fabric development has previously been observed in the Vostok ice core from East Antarctica, where converging flow is believed to occur. The most likely interpretation of the NorthGRIP girdle fabric is that the $c$ axes are rotating away from a horizontal-tension axis across the main ice divide, which runs north-northwest-south-southeast through the NorthGRIP drilling site. This is supported by information available from surface velocity measurements. Within the girdle fabric, increased concentration of $c$ axes parallel to the core axis is observed with increasing depth, indicating combined effects of vertical compression and horizontal tension on the fabric development. From about $2500 \mathrm{~m}$ depth, the girdle-type fabric starts to give way to a strong vertical single-maximum fabric, which persists to $2920 \mathrm{~m}$ depth, where drilling was terminated $150 \mathrm{~m}$ above bedrock in the year 2000 . The single maximum seems to suggest that bed-parallel simple shear is exerting a strong influence on the fabric in the lowest part of the ice sheet down to $2920 \mathrm{~m}$.
\end{abstract}

\section{INTRODUGTION}

Crystal-fabric analysis on deep ice cores drilled on polar ice sheets yields important information on their internal deformation and flow patterns. Studies on ice cores from Greenland and Antarctica have revealed that $c$-axis orientations evolve from random patterns near the surface to highly preferred orientations in the lower parts of the ice sheets. The type of fabric that develops depends on the dominant stress system, and the fabric strength seems to be mainly determined by the cumulative strain (e.g. Alley, 1988; Budd and Jacka, 1989). At locations near ice-sheet summits (e.g. GRIP and GISP2, central Greenland) or local domes (e.g. Dome F, East Antarctica), where vertical uniaxial compression dominates, a strong vertical single-maximum fabric develops (Gow and others, 1997; Thorsteinsson and others, 1997; Azuma and others, 1999). On the other hand, a vertical girdle fabric is observed to form in ice-sheet regions with a strong component of horizontal tension, well-known examples being the Vostok and Mizuho sites, East Antarctica (Fujita and others, 1987; Lipenkov and others, 1989). Rotation of $c$ axes by basal glide is the generally accepted mechanism for fabric develop- ment (Azuma and Higashi, 1985; Alley, 1988). The crystalline anisotropy revealed by fabric measurements affects ice-sheet deformation. Clear evidence of enhanced horizontal shear deformation rates of ice displaying a single-maximum fabric has been found by inclination measurements in the boreholes, and laboratory studies indicate that such ice is significantly harder against vertical compression than ice with a random fabric (Dahl-Jensen and Gundestrup, 1987; Shoji and Langway, 1988; Paterson, 1991; Dahl-Jensen and others, 1997a, b). Effects of fabric development on ice deformation are now increasingly being taken into account in models of ice-sheet flow (Azuma, 1994; Azuma and Goto-Azuma, 1996; Thorsteinsson and others, 1999; Cuffey and others, 2000).

In this work, results are presented from a study of $c$-axis fabrics in the new North Greenland Icecore Project (NorthGRIP) deep core drilled in the years 1999-2001 at the location $75^{\circ} 1^{\prime} \mathrm{N}, 42^{\circ} 3^{\prime} \mathrm{W}$. $c$-axis orientations have been measured on 142 thin sections from $120 \mathrm{~m}$ down to $2930 \mathrm{~m}$, the depth reached by the end of the 2000 drilling season. The measurements have mainly been carried out with a new automatic icefabric analyzer (AIFA; Wang and Azuma, 1999), but manual measurements using conventional methods have been per- 


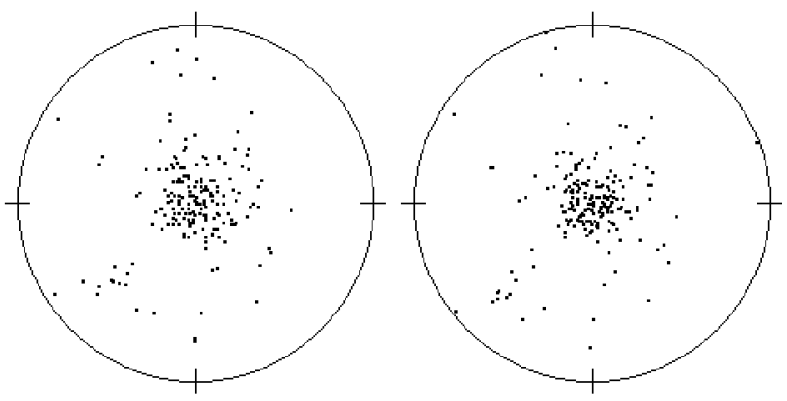

Fig. 1. Comparison of a crystal-orientation fabric measured manually with a universal stage (left) and automatically with the AIFA (right). The sample is from $2900 \mathrm{~m}$ depth, and 200 crystals are measured.

formed at selected depths as well, for comparison. In addition to presenting the fabrics and statistics derived from them, the paper addresses the stress conditions and the ice-flow pattern at the NorthGRIP site. Results from crystal-size measurements are reported elsewhere.

\section{METHODS}

\section{Sampling and thin-section preparation}

The NorthGRIP project was initiated in 1996. In 1997, the drill became stuck at $1370 \mathrm{~m}$ depth, and drilling had to be restarted from the surface in 1999, $20 \mathrm{~m}$ from the previous position. In the 2000 season, a depth of $2930 \mathrm{~m}$ was reached, $150 \mathrm{~m}$ above bedrock. All measurements in the depth interval 100-1370 $\mathrm{m}$ were performed on samples cut at 55-66 $\mathrm{m}$ intervals from the first core (NorthGRIP 1). Samples from the brittle zone $(650-1300 \mathrm{~m})$ were cut after 3 years of relaxation. From the second core (NorthGRIP 2), a continuous $1.2 \mathrm{~cm}$ thick strip was cut from the side, along the entire core length. A total of 300 samples have been cut from this strip at depths of $1370-2930 \mathrm{~m}$.

Vertical thin sections, $9 \mathrm{~cm}$ long and $6 \mathrm{~cm}$ wide, were prepared from the strip samples. The flat side of the strip sample was smoothed with a microtome, then placed on a $110 \times 70 \times 2 \mathrm{~mm}$ glass plate and frozen onto it by dropping water along the edge. Then the section was reduced in thickness to $2 \mathrm{~mm}$ with a band-saw and finally down to $0.5 \mathrm{~mm}$ with a microtome. Silicone oil was applied to the surface of the thin section to prevent sublimation. The thin sections were packed in plastic bags and stored at a temperature of $-25^{\circ} \mathrm{C}$.

\section{Instrument}

The $c$-axis orientation measurements have been performed with an AIFA, described in detail in Wang and Azuma (1999). In this instrument, the ice thin sections are placed between a pair of crossed polarizers and imaged from nine different positions with a charge coupled device camera. At the first (vertical) observing position, the crossed polarizers are rotated $90^{\circ}$, and images taken of the thin section every $5^{\circ}$. Analysis with image-processing techniques is then used to distinguish crystal boundaries and obtain textural information on crystal size, aspect ratio and elongation direction. Checking and comparing the pictures, 200 crystals are arbitrarily selected by mouse-clicking within an area of $5 \times 5 \mathrm{~cm}$ (or larger if a larger crystal size makes it necessary). The coordinates of each selected crystal in the image are saved

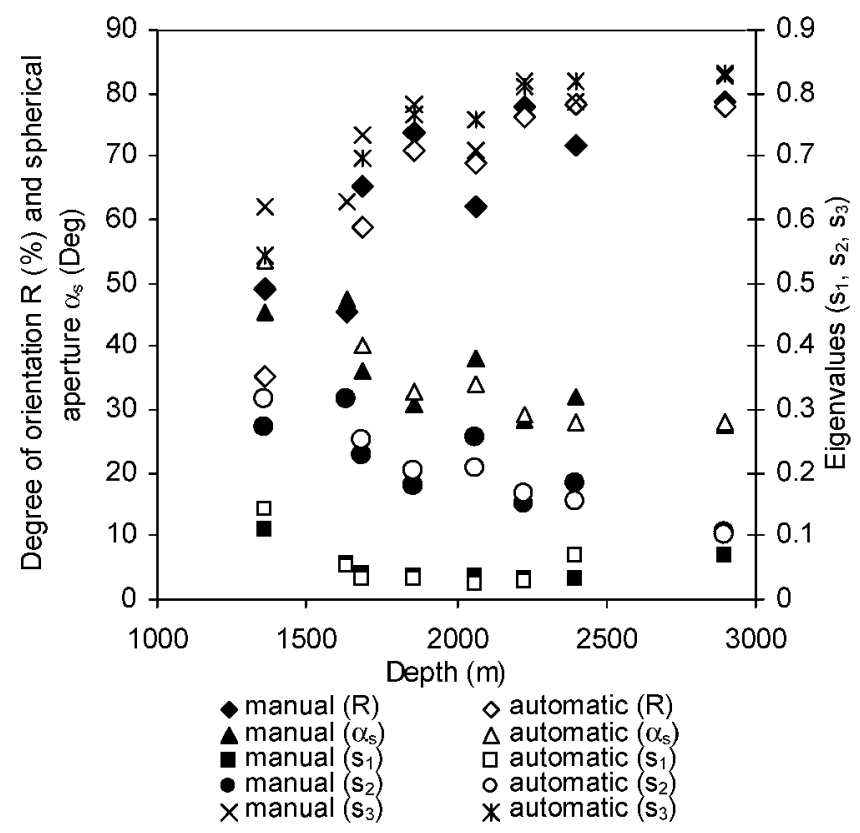

Fig. 2. Statistical comparison of manual and automatic fabric measurement results.

and converted to new coordinates at the other observing positions of the camera. At these positions, imaging of the thin sections at different rotation positions of the polarizers is repeated. From the pictures, the brightness at each selected crystal coordinate is measured and the extinction position of each crystal calculated. The $c$-axis orientation can then be determined from the geometrical relation of the extinction positions in different observing positions. Except for the manual selection of crystals, the routine has been done automatically. The procedure used in this work has been changed from that described inWang and Azuma (1999), to avoid difficulties in determining the orientations of very small crystals. For comparison, several samples were measured both with the conventional universal-stage method and with the AIFA. As is evident from Figure 1, the results from the two types of measurements are in good agreement. The average difference between inclination values for 200 crystals is $3^{\circ}$, and the same average difference is obtained for the azimuth results. Figure 2 shows a statistical comparison between the manual and automatic results, again indicating good agreement (see next subsection on statistics definitions).

\section{Data treatment}

The $c$-axis orientations have been plotted on the lower hemisphere of an equal-area Schmidt net. All measured data from vertical thin sections were rotated such that the diagrams show $c$-axis orientations as viewed in a horizontal plane, from above. The computer program "Ariane" has been used to calculate the following statistical parameters.

The degree of orientation $(R)$ has been defined by Wallbrecher (1978) as

$$
R(\%)=\frac{2|S|-N}{N} \times 100
$$

where each $c$ axis is treated as a unit vector, $S$ is the length of the vector sum and $N$ is the number of $c$ axes. $R$ varies between $0 \%$ for a random distribution and $100 \%$ for completely parallel orientations and can be used as a measure of fabric strength. 


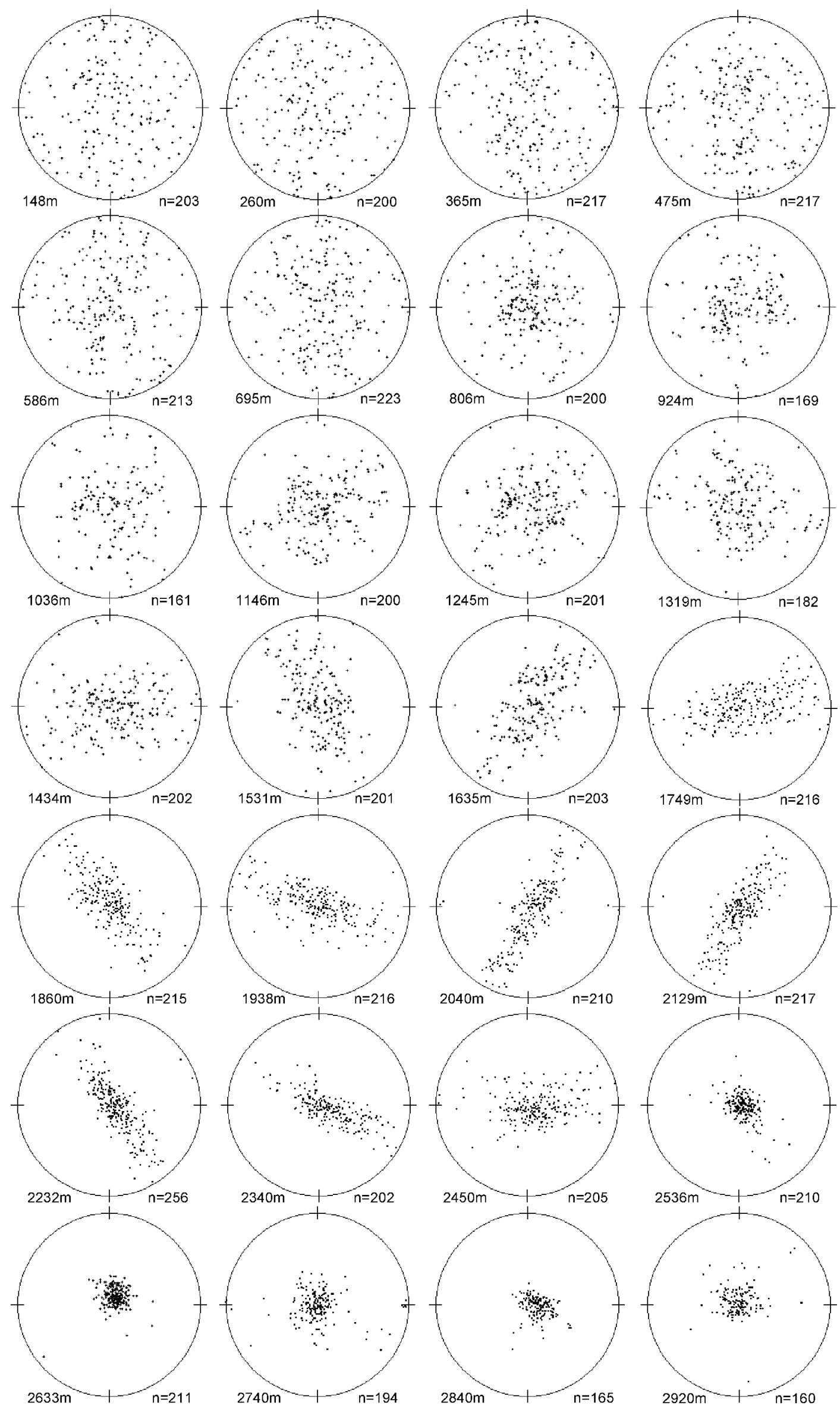

Fig. 3. Horizontal view of fabric diagrams of vertical thin sections through the depth at an interval of about $100 \mathrm{~m}$. The centre of each diagram represents the vertical direction. 


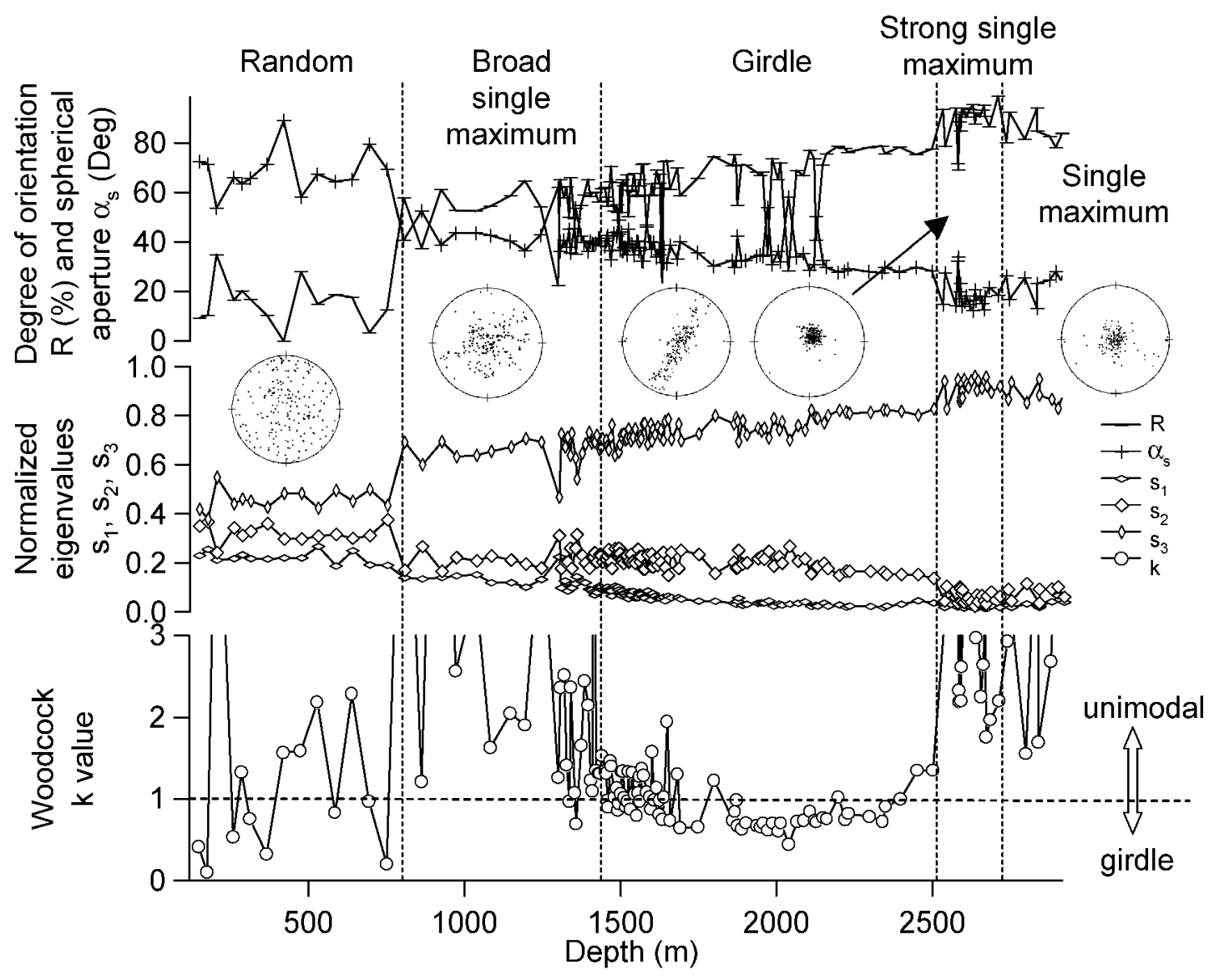

Fig. 4. Statistical results as a function of depth. The vertical dashed lines divide the depth into five regimes according to Table 1. The typical fabric diagram in each regime is also shown. They are from 148, 1146, 2040, 2633 and $2740 \mathrm{~m}$, respectively. Note that these depths do not correspond exactly to the positions of the diagrams.

Another parameter that can be used to describe the fabric strength is spherical aperture $\left(\alpha_{\mathrm{s}}\right)$, expressed as

$$
\alpha_{\mathrm{s}}=\arcsin \left(\sqrt{2 \frac{1-(1 / N)}{(N-1) /(N-|s|)}}\right) .
$$

$\alpha_{\mathrm{S}}$ can be described as the radius of a circle centred on the average $c$ axis in the fabric diagram, and containing within it a uniform distribution of $c$ axes which have the same $R$ value as the measured distribution. Eigenvectors and eigenvalues calculated by the program provide a measure of fabric shape. The eigenvectors represent three orthogonal vectors parallel to the axes of an ellipsoid which best fits the shape of the $c$-axis distribution, and the eigenvalues equal the lengths of these axes. In this work, normalized (i.e. divided by the number of axes) eigenvalues $\left(s_{1}, s_{2}, s_{3}\right)$ are presented. The largest eigenvalue, $s_{3}$, can be used as a fabric concentration parameter. Furthermore, we calculate the Woodcock $k$ value defined by Woodcock (1977),

$$
k=\frac{\ln \left(s_{3} / s_{2}\right)}{\ln \left(s_{2} / s_{1}\right)},
$$

which can be used to distinguish between unimodal and girdle fabrics. The parameter $k$ lies in the interval $[0,1]$ for girdle fabrics and $[1, \infty]$ for unimodal fabrics.

\section{RESULTS}

\section{Schmidt net}

Figure 3 displays fabric diagrams measured on samples cut from 28 different depth levels in the NorthGRIP core, with intervals averaging $100 \mathrm{~m}$. All diagrams display $c$-axis orientations measured on vertical thin sections and rotated into horizontal view. The centre of the diagram thus represents the vertical axis along the core. The $c$-axis orientations appear uniform in the uppermost $750 \mathrm{~m}$. At $805 \mathrm{~m}$ depth a broad single maximum has been formed, and at 1300$1750 \mathrm{~m}$ a marked clustering of the $c$ axes towards the vertical plane is observed. This vertical girdle-fabric pattern further strengthens with depth, and persists down to about $2500 \mathrm{~m}$, forming the first clear evidence of this fabric type in a Greenland deep ice core. The azimuth of the girdle plane is not known, but here the diagrams are shown assuming a common azimuth for the girdles. Below $2500 \mathrm{~m}$ depth, the fabric transforms to a strong single maximum that displays variable streng th down to $2920 \mathrm{~m}$.

\section{Statistical parameters}

The degree of orientation $(R)$, spherical aperture $\left(\alpha_{\mathrm{s}}\right)$, eigenvalues $s_{1}, s_{2}$ and $s_{3}$, and Woodcock $k$ value are shown in Figure. 4. $R, \alpha_{\mathrm{s}}$ and $s_{3}$ indicate general strengthening of the fabric through the entire depth of the core. At $805 \mathrm{~m}$, there is a sudden increase in the $c$-axis concentration, reflecting the formation of a broad single-maximum fabric pattern. Another sharp increase in fabric strength occurs at $2587 \mathrm{~m}$ depth, indicating the transition from a girdle fabric to a strong single maximum. Eigenvalues $s_{1}$ and $s_{2}$ show a general decreasing trend through the depth. However, at 1400-1500 m depth, $s_{2}$ stops decreasing and starts a slight increase while $s_{1}$ continues decreasing. This variation can clearly be observed from the Woodcock $k$ value, which at this 
Table 1. The fabric zones divided according to statistical parameters and fabric diagrams

\begin{tabular}{|c|c|c|c|c|c|c|}
\hline Fabric zone & $\begin{array}{l}\text { Depth } \\
\mathrm{m}\end{array}$ & $\begin{array}{c}\text { Degree of orientation, } R \\
\%\end{array}$ & Spherical aperture, $\alpha_{\mathrm{S}}$ & Eigenvalues, $s_{1}, s_{2}, s_{3}$ & Woodcock kvalue & Fabric diagram shape \\
\hline 1 & $100-750$ & $\leq 20$ & $\approx 60-85$ & $s_{1} \approx s_{2} \approx s_{3} \approx 1 / 3$ & - & Random \\
\hline 2 & $800-1500$ & $\approx 60$ & $\approx 40$ & $0 \leq s_{1} \leq s_{2} \approx 1 / 3 \leq s_{2} \leq 2 / 3$ & $>1$ & Broad single maximum \\
\hline 3 & $1500-2587$ & $60-80$ & $25-40$ & $s_{1} \approx 0 \leq s_{2} \leq 1 / 2 \leq s_{3} \leq 1$ & $<1$ & Girdle \\
\hline 4 & $2587-2740$ & $\approx 100$ & $\approx 18$ & $s_{1} \approx s_{2} \approx 0, s_{3} \approx 1$ & $>1$ & Strong single maximum \\
\hline 5 & $2740-2930$ & $\approx 80$ & $\approx 22$ & $\begin{array}{c}0 \leq s_{1} \approx s_{2} \leq 1 / 6 \\
2 / 3 \leq s_{3} \leq 1\end{array}$ & $<1$ & Single maximum \\
\hline
\end{tabular}

depth indicates a fabric change from a unimodal $(k>1)$ to a girdle $(k<1)$ pattern. $s_{2}$ remains constant down to about $1800 \mathrm{~m}$ where $s_{1}$ and $k$ both reach minima. After this depth, $s_{2}$ decreases again with slightly increasing $s_{1}$, which results in $k$ increasing and finally switching back from a girdle to a unimodal pattern at around $2500 \mathrm{~m}$ depth. Here, $s_{3}$ reaches its maximum as both $s_{2}$ and $s_{1}$ approach zero. Below $2700 \mathrm{~m}$, a slight decrease of $s_{3}$ and increase of $s_{2}$ can be observed. Based on the variation in statistical parameters and the appearance of the fabric diagrams, the core can be divided into five fabric zones as shown in Table 1.

\section{DISGUSSION}

Single crystals of ice mainly deform by gliding on their basal planes. Although crystals unfavourably oriented for basal glide can still deform by gliding along prismatic and pyramidal planes, the stress needed to produce a given deformation is up to 100 times higher in this case than for basal glide. In polycrystalline ice, each crystal is constrained by its neighbours, so the crystals have to take up rotation as they deform by basal glide. Being perpendicular to the basal planes, the $c$ axis rotates away from an axis of extension and towards a compression axis. It has recently been argued that grain-boundary sliding can contribute significantly to ice deformation (Peltier and others, 2000; Goldsby and Kohlstedt, 2001). However, the experiments upon which this conclusion was based were performed on artificial, ultrafine-grained ice - much more fine-grained than found in natural ice sheets and glaciers - and have then been extrapolated to larger grain-sizes. Moreover, the relatively high temperatures and stresses used in most laboratory creep experiments cannot really reflect the conditions in natural ice masses. Duval and others (2000) concluded that basal glide is the predominant deformation mode of polar ice.

From experiments with unconfined compression of thin specimens of natural and artificial ice, Azuma and Higashi (1985) found that the strain in each grain was approximately proportional to the Schmid factor for the slip direction, with the bulk strain equal to the strain of individual grains averaged over the entire sample. A numerical simulation of the observed fabric development successfully reproduced a fabric observed at $800 \mathrm{~m}$ depth in the Dye 3 core. The model used assumes that ice deforms only by basal glide and that no recrystallization occurs. This model has also been used successfully to simulate fabric development in uniaxial tension in the Mizuho (Fujita and others, 1987) and Vostok ice cores (Lipenkov and others, 1989), and Alley (1988) applied it to four types of stress conditions: uniaxial compression, uniaxial tension, pure shear and simple shear. His simulation results showed that the random fabric observed in the uppermost parts of polar ice sheets transforms to a single maximum at depth in the case of uniaxial compression, to a girdle pattern in the case of uniaxial extension, to a single maximum which is elongated in the direction perpendicular to the axis of tension in the case of pure shear, and to a single-maximum fabric centred on the vertical in the case of simple shear.

Observing the Schmidt diagrams and the calculated statistical parameters, especially the eigenvalues and the Woodcock $k$ value, we find that with increasing depth the fabric changes from random through a broad single maximum to an elongated single maximum at around $1400 \mathrm{~m}$. Below this, the vertical girdle fabric starts to form ( $k$ enters $<1$ regime). This girdle fabric strongly resembles fabrics observed to develop in the Vostok ice core (Lipenkov and others 1989), due to rotation of $c$ axes away from an axis of horizontal tension.

We now discuss the formation of the vertical girdle fabric in the NorthGRIP core. Hvidberg and others (2002) have used surface velocity measurements in the NorthGRIP area to calculate surface strain rates as

$$
\begin{aligned}
& \dot{\varepsilon}_{1}=(-0.4 \pm 0.3) \times 10^{-5} \mathrm{a}^{-1} \\
& \dot{\varepsilon}_{2}=(7.4 \pm 0.5) \times 10^{-5} \mathrm{a}^{-1}
\end{aligned}
$$

in the directions along and transverse to the ice-divide ridge, respectively. The negative strain rate along the ridge shows that the ice is slowed down as it moves along the northnorthwest ridge. Compared with the deformation rate along the ridge, the one transverse to the ridge is about 20 times larger. The ice can be assumed to be undergoing extension transverse to the ridge, slight compression along the ridge and compression in the vertical direction at almost the same strain rate as $\dot{\varepsilon}_{2}$. The deformation in the upper part of the ice sheet at NorthGRIP can thus be described as confined compression. The plane of the vertical girdle fabric can be assumed to lie in the direction of the ridge, perpendicular to the axis of horizontal extension.

The change from a girdle fabric to a strong single maximum at about $2500 \mathrm{~m}$ depth suggests that simple shear deformation occurs in the lowest part of the ice sheet at NorthGRIP. Although a comparison between the fabrics at $2450 \mathrm{~m}$ and $2536 \mathrm{~m}$ suggests a rapid transformation, it seems clear that the $c$ axes start concentrating towards the middle of the girdle fabric as soon as it has been formed, but are not uniformly distributed throughout the girdle. This visual interpretation of the fabrics is supported by the increasing trend in $k$ values below $2000 \mathrm{~m}$ depth (Fig. 4). A gradual onset of simple shear deformation can thus be inferred from these data.

The effect of the observed fabrics on internal ice-sheet deformation is not clear. The girdle fabric will have some 
crystals in a "hard" position against vertical compression, but some will be in a "soft" position, with their $c$ axes at or near $45^{\circ}$ from the vertical compression axis. Similarly, some crystals in this fabric will be in positions favourable for simple shear, whereas others will not. The effect on the thinning rate of the annual layers in the ice cannot be inferred with certainty. Once the single maximum is formed, simple shear deformation will continue to strengthen that fabric, and such a strengthening seems to occur in the interval 2536$2633 \mathrm{~m}$ (Fig. 3). Variation in the fabric strength below $2633 \mathrm{~m}$ can be due to varying impurity content and crystal size, or to the onset of migration recrystallization at higher temperatures near the bed, producing more open fabrics (Van der Veen and Whillans, 1994; De La Chapelle and others, 1998). Significant changes in stress conditions near the bed can also lead to variations in fabric strength (Budd and Jacka, 1989), but this is not likely to be important in the NorthGRIP region, where the ice-sheet bed is relatively flat (Dahl-Jensen and others, 1997a,b).

\section{GONGLUSION}

A high-resolution study of $c$-axis fabrics has been performed on the NorthGRIP ice core using an AIFA. From the visual appearance of the fabrics and statistical studies, the core can be divided into five zones with varying fabric characteristics at depths between 100 and $2920 \mathrm{~m}$. This information, combined with results from surface velocity measurements, suggests that the upper two-thirds of the ice sheet at NorthGRIP is undergoing confined compression, i.e. a combination of vertical compression, horizontal tension across the ice divide and horizontal compression along the divide. The well-defined vertical girdle fabric in the depth interval $1500-2500 \mathrm{~m}$ is the first clear observation of such a fabric in a Greenland deep ice core. In the lower third of the ice sheet, the effect of bed-parallel simple shear can be seen in the fabric development, and vertical single-maximum fabrics dominate below $2500 \mathrm{~m}$ depth. When borehole data on internal icesheet deformation at NorthGRIP become available, it will be possible to learn more about the effect of the fabric changes observed in the core on the rheology of the ice sheet. Such information is crucial for the improvement of ice-sheet models that take into account the development of crystalline anisotropy.

\section{ACKNOWLEDGEMENTS}

We thank N. Azuma for helpful suggestions, and two anonymous reviewers for their valuable comments. This work is a contribution to the NorthGRIP ice-core project, which is directed and organized by the Department of Geophysics at the Niels Bohr Institute for Astronomy, Physics and Geophysics, University of Copenhagen. It is being supported by funding agencies in Denmark, Belgium, France, Germany, Iceland, Japan, Sweden, Switzerland and the United States. Th. Thorsteinsson thanks the Icelandic Research Council (RannIs) for support.

\section{REFERENGES}

Alley, R. B. 1988. Fabrics in polar ice sheets: development and prediction. Science, 240(4851), 493-495.

Azuma, N. 1994. A flow law for anisotropic ice and its application to ice sheets. Earth Planet. Sci. Lett., 128(3-4), 601-614.

Azuma, N. and K. Goto-Azuma. 1996. An anisotropic flow law for ice-sheet ice and its implications. Ann. Glaciol., 23, 202-208.

Azuma, N. and A. Higashi. 1985. Formation processes of ice fabric pattern in ice sheets. Ann. Glaciol., 6, 130-134.

Azuma, N. and6 others. 1999. Textures and fabrics in the Dome F (Antarctica) ice core. Ann. Glaciol., 29, 163-168.

Budd, W. F. and T. H. Jacka. 1989. A review of ice rheology for ice sheet modelling. Cold Reg. Sci. Technol., 16(2), 107-144.

Cuffey, K. M., H. Conway, A. Gades, B. Hallet, C. F. Raymond and S. Whitlow. 2000. Deformation properties of subfreezing glacier ice: role of crystal size, chemical impurities, and rock particles inferred from in situ measurements. F. Geophys. Res., 105(B12), 27,895-27,915.

Dahl-Jensen, D. and N. S. Gundestrup. 1987. Constitutive properties of ice at Dye 3, Greenland. International Association of Hydrological Sciences Publication 170 (Symposium at Vancouver 1987 — The Physical Basis of Ice Sheet Modelling , 31-43.

Dahl-Jensen, D., T. Thorsteinsson, R. Alley and H. Shoji. 1997a. Flow properties of the ice from the Greenland Ice Core Project ice core: the reason for folds? 7. Geophys. Res., 102(C12), 26,831-26,840.

Dahl-Jensen, D. and 9 others. 1997b. A search in north Greenland for a new ice-core drill site. F. Glaciol., 43(144), 300-306.

De La Chapelle, S., O. Castelnau, V. Lipenkov and P. Duval. 1998. Dynamic recrystallization and texture development in ice as revealed by the study of deep ice cores in Antarctica and Greenland. 7. Geophys. Res., 103(B3), 5091-5105.

Duval, P., L. Arnaud, O. Brissaud, M. Montagnat and S. de la Chapelle. 2000. Deformation and recrystallization processes of ice from polar ice sheets. Ann. Glaciol., 30, 83-87.

Fujita, S., M. Nakawo and S. Mae. 1987. Orientation of the 700-m Mizuho core and its strain history. Proc. NIPR Symp. Polar Meteorol. Glaciol. 1, 122-131.

Goldsby, D. L. and D. L. Kohlstedt. 2001. Superplastic deformation of ice: experimental observations. 7. Geophys. Res., 106(B6), 11,017-11,030.

Gow, A. J. and 6 others. 1997. Physical and structural properties of the Greenland Ice Sheet Project 2 ice cores: a review. 7. Geophys. Res., 102(C12), 26,559-26,575.

Hvidberg, C. S., K. Keller and N. S. Gundestrup. 2002. Mass balance and ice movement along the north-northwest ridge of the Greenland ice sheet at NorthGRIP. Ann. Glaciol., 35 (see paper in this volume).

Lipenkov, V.Ya., N. I. Barkov, P. Duval and P. Pimienta. 1989. Crystalline texture of the $2083 \mathrm{~m}$ ice core at Vostok Station, Antarctica. F. Glaciol., 35(121), 392-398

Paterson, W. S. B. 1991. Why ice-age ice is sometimes "soft". Cold Reg. Sci. Technol., 20(1), 75-98

Peltier, W. R., D. L. Goldsby, D. L. Kohlstedt and L. Tarasov. 2000. Ice-age ice-sheet rheology: constraints from the Last Glacial Maximum form of the Laurentide ice sheet. Ann. Glaciol., 30, 163-176.

Shoji, H. and C. C. Langway, Jr. 1988. Flow-law parameters of Dye 3, Greenland, deep ice core. Ann. Glaciol., 10, 146-150.

Thorsteinsson, Th., J. Kipfstuhl and H. Miller. 1997. Textures and fabrics in the GRIP ice core. F. Geophys. Res., 102(C12), 26,583-26,599.

Thorsteinsson, T., E. D. Waddington, K. C. Taylor, R. B. Alley and D. D. Blankenship. 1999. Strain-rate enhancement at Dye 3, Greenland. $\mathcal{f}$ Glaciol., 45(150), 338-345

Van der Veen, G. J. and I. M. Whillans. 1994. Development of fabric in ice. Cold Reg. Sci. Technol., 22(2), 171-195.

Wallbrecher, E. 1978. Ein Cluster-Verfahren zur richtungsstatistischen Analyse tektonischer Daten. Geol. Rundsch., 67, 840-857.

Wang Yun and N. Azuma. 1999. A new automatic ice-fabric analyzer which uses image-analysis techniques. Ann. Glaciol., 29, 155-162.

Woodcock, N. H. 1977. Specification of fabric shapes using an eigenvalue method. Geol. Soc. Am. Bull., 88, 1231-1236. 